\title{
Efectividad del Acido Peracético sobre la reducción de la carga de Esporas de Mohos causantes de Pudrición Poscosecha de Frutas y Hortalizas
}

\author{
María V. Kyanko(1)$^{(1)}$ Mara L. Russo ${ }^{(1)}$, Mariela Fernández ${ }^{(1)}$, Graciela Pose $^{(2)}$ \\ (1) Universidad Nacional de Quilmes (2) CONICET, Roque Saenz Peña 352, C.P. 1876, \\ Bernal, Buenos Aires, Argentina, (e-mail: npose@unq.edu.ar)
}

Recibido Jun. 03, 2009; Aceptado Ago. 10, 2009; Versión Final recibida May. 14, 2010

\begin{abstract}
Resumen
Se evaluó in vitro la efectividad del ácido peracético sobre la reducción de la carga de esporas de mohos micotoxicogénicos causantes de pudrición de frutas y hortalizas, para determinar su potencial aplicación al control poscosecha de esta patología. Se evaluó tres concentraciones de ácido $(0.05 \%, 0.1 \%$ y $0.3 \%)$ para determinar su capacidad antifúngica frente a Alternaria alternata, Fusarium graminearum, Aspergillus ochraceus, $A$. níger, A. flavus, Penicillium roqueforti y $P$. expansum. Se observó una reducción de la carga de esporas aún a la más baja concentración ensayada, efecto que incrementó con el aumento de la concentración del tratamiento. A una concentración del $0.3 \%$ se logró una mucho mayor reducción de la carga de esporas viables de $A$. alternata, F. graminearum y A. ochraceus, respectivamente. El ácido peracético podría resultar una alternativa de tratamiento no contaminante para el control poscosecha de la pudrición fúngica.
\end{abstract}

Palabras clave: ácido peracético, esporas fúngicas, capacidad antifúngica, pudrición de vegetales

\section{Effectiveness of Peracetic Acid on fungal Spores reduction of Moulds causing rotting in Fruits and Vegetables}

\begin{abstract}
The objective of this work was to determine in vitro the effectiveness of peracetic acid on the load reduction of mould spores that are responsible for rotting in fruits and vegetables to evaluate its potential application to post-harvest control. Three concentrations of peracetic acid $(0.05 \%, 0.1 \%$ and $0.3 \%$ ) were used to evaluate its anti-fungal capacity against Alternaria Alternata, Fusarium graminearum, Aspergillus ochraceus, A. niger, A. flavus, Penicillium roqueforti and $P$. expansum. It was observed reduction of the load of spores using the lowest concentration. This effect was increased with a higher concentration of peracetic acid. It was extremely effective at a concentration of $0.3 \%$ against $A$. alternata, $F$. graminearum and $A$. ochraceus. It is concluded that the peracetic acid is a nonpolluting alternative treatment for post-harvest rotting control of fruits and vegetables
\end{abstract}

Keywords: peracetic acid, fungal spores, anti-fungal capacity, rotting in fruits and vegetables. 


\section{INTRODUCCIÓN}

Durante el tiempo que transcurre entre la cosecha de frutas y hortalizas y el consumo de estas puede producirse sobre los productos la pérdida de su calidad debido a cambios físicos, químicos, enzimáticos o microbiológicos. Las consecuencias de la pérdida de calidad debida a la acción de microorganismos supone, además de las pérdidas económicas causadas por la alteración, un riesgo para la salud del consumidor debido a la posible presencia de toxinas o microorganismos patógenos (Raybaudi-Mansilla et al., 2006). Los hongos son los causantes del deterioro patológico de frutas con mayor frecuencia. Las frutas son usualmente ácidas en un rango de $\mathrm{pH}$ de 1,8 - 2,2 lo que les proporciona mayor resistencia frente a las bacterias, algo que no sucede en vegetales, que al tener un $\mathrm{pH}$ cercano al neutro los hace igualmente vulnerables tanto a hongos como a bacterias (Pitt y Hocking, 1997).

Respecto a los mohos responsables del deterioro poscosecha de frutas y hortalizas, las especies mas comúnmente asociadas pertenecen a los géneros Fusarium, Alternaria, Penicillium y Aspergillus. Fusarium es uno de los géneros más importantes de hongos patógenos de plantas, con un elevado número de infecciones devastadoras en muchos cultivos importantes económicamente, especialmente de cereales, y también verduras y frutas. Es capaz de causar importante deterioro poscosecha, particularmente de estas últimas. El género Fusarium contiene especies importantes productoras de micotoxinas que han sido asociadas a enfermedades humanas y animales (Logrieco et al., 2003). Los mohos del género Alternaria están ampliamente distribuidos en la naturaleza. Este incluye tanto especies patógenas de plantas como saprobias, capaces de dañar los cultivos a campo como también de causar un deterioro importante durante el almacenamiento y transporte, aún refrigerado (Bottalico y Logrieco, 1992). Las especies de Alternaria son capaces de producir al menos 70 metabolitos secundarios tóxicos (King y Schade, 1984). Los mohos de los géneros Aspergillus y Penicillium desarrollan sobre los más diversos sustratos, incluyendo frutas y hortalizas. La importancia de estos mohos en la alimentación humana y animal se debe a que, además de causar deterioro, también ellos producen micotoxinas (Carrillo, 2007).

El uso de agentes químicos en el control de hongos y pudriciones en algunas frutas y hortalizas mediante la aplicación poscosecha de fungicidas y pesticidas ha sido una práctica común. Sin embargo, el uso de estos compuestos químicos se ha restringido debido a sus efectos carcinógenos, teratogénicos, alta residuabilidad, período largo de degradación, contaminación ambiental y otros efectos negativos (Bautista Baños, 2006). Sin embargo, no existen todavía a disposición del sector agroalimentario tratamientos no contaminantes alternativos a los fungicidas químicos que controlen las enfermedades poscosecha de manera eficaz y a un costo efectivo sin incidir negativamente en la calidad del producto (Palou, 2007). Alternativas prometedoras son la aplicación de lavados con soluciones de ácidos orgánicos, acido peracético o peróxido de hidrogeno como también la aplicación de aceites esenciales y oleorresinas y péptidos antimicrobianos. Los péptidos antimicrobianos son un abundante y diverso grupo de moléculas producidas por muchos tejidos y tipos de células de varias especies de invertebrados, plantas y animales (Brogden, 2005). Distintos péptidos se han estudiado y aplicado en condiciones experimentales al control de la podredumbre poscosecha de frutos cítricos producida por $P$. digitatum. Estos péptidos han mostrado actividad protectora aun a bajas concentraciones (Muñoz, 2008). Llevar a cabo estudios referidos a esta problemática resulta sumamente necesario tanto para este sector como para los consumidores de su producción.

El ácido peracético es un eficaz desinfectante que consiste en una combinación de peróxido de hidrógeno y ácido acético. Este actúa de una manera similar a la de los clorógenos, es decir, con un amplio poder oxidante, pero, a diferencia de los primeros, su acción es mucho menos corrosiva, posee un mayor espectro de acción y es efectivo en presencia de materia orgánica y de aguas duras. Asimismo, el ácido peracético no afecta al medio ambiente y se descompone en poco tiempo dejando como residuo agua, oxígeno y ácido acético. Además, por requerir bajas concentraciones su costo es moderado. El ácido peracético no mancha y si se almacena concentrado resulta estable durante largo tiempo (S.E.N.A.S.A., 2006). Debido a su capacidad antimicrobiana y a que sus productos de descomposición son totalmente biocompatibles porque no deja residuos tóxicos, la FDA (Food and Drug Administration) ha aprobado el uso del ácido peracético para la desinfección directa 
de frutas y hortalizas (FDA, 2001). Varios trabajos reportan su eficacia desinfectante frente a bacterias, tanto in vitro como sobre los productos (Wright et al., 2000; López et al., 2001; López et al., 2002; Rodgers et al., 2004; Bastos et al., 2005; Srebernich, 2007; Silveira et al., 2008), sin embargo, existen pocos estudios en relación a su acción antifúngica (Mari et al., 1999; Garmendia y Vero Méndez, 2006; Salomão et al., 2008).

El objetivo del presente trabajo fue determinar in vitro la efectividad del ácido peracético sobre la reducción de la carga de esporas de mohos causantes de pudrición de frutas y hortalizas a fin de determinar su potencial aplicabilidad al control poscosecha de esta patología.

\section{MATERIALES Y METODOS}

Tres concentraciones de ácido peracético (0,05\%, 0,1\% y 0,3\%) fueron evaluadas en su capacidad antifúngica sobre cuatro géneros fúngicos. Particularmente, las especies evaluadas fueron Alternaria alternata, Fusarium graminearum, Aspergillus ochraceus, A. níger, A. flavus, Penicillium roqueforti y $P$. expansum, reportadas causantes de alteración poscosecha de frutas y hortalizas. El ensayo se llevo a cabo empleando el método de suspensión (Hernández Rodríguez, 2006). Tubos conteniendo las soluciones de las diferentes concentraciones de ácido peracético y un tubo control con agua (no tratamiento) fueron inoculados con una suspensión de esporas de cada uno de los mohos evaluados a una concentración final de $10^{5}-10^{6}$ esporas $/ \mathrm{ml}$. La concentración final de la solución de esporas fue determinada por recuento en cámara de Neubauer.

Luego de transcurrido el tiempo de exposición (30 min.), $1 \mathrm{ml}$ de la suspensión fue transferida a un tubo con agua de peptona $0,1 \%$ (neutralización). Se realizaron diluciones seriadas y se llevó a cabo el recuento en placa de las esporas sobrevivientes sobre Agar Extracto de Malta (AEM). Las placas se incubaron durante $24 / 48$ hs a $25^{\circ} \mathrm{C}$. La experiencia se llevo a cabo dos veces por duplicado. Para el análisis estadístico se utilizó el test de Kruskall-Wallis y posteriormente se aplicó el test de comparaciones múltiples de Dunn, comparando cada tratamiento respecto al control para cada especie fúngica.

\section{RESULTADOS Y DISCUSIÓN}

Los resultados obtenidos respecto a la reducción de la carga de esporas para cada especie fúngica y para cada concentración de ácido peracético evaluada están expresados en la Tabla1. Los resultados mostrados en la Tabla son expresados en ufc/ml (log esporas $/ \mathrm{ml}$ ) y como el promedio de los dos tratamientos \pm la Desviación Estándar. Los valores seguidos por la misma letra dentro de una fila no son significativamente diferentes $(p<0,05 \%)$ por el test de Dunn.

A la más baja concentración de ácido peracético evaluada $(0,05 \%)$ no se han observado diferencias significativas respecto al tratamiento control (agua), si bien logró reducir en más un orden logarítmico la población de esporas viables de $F$. graminearum y $A$. alternata $(1,45$ y 1,35 ordenes logarítmicos respectivamente). También a esta concentración se logró una reducción decimal de 0,89 en la carga de esporas viables de $A$. ochraceus. Asimismo, 0,31 y 0,30 reducciones decimales se han observado por exposición a la más baja concentración de ácido peracético evaluada para especies de Aspergillus ( $A$. níger y $A$. flavus, respectivamente). En el caso de $P$. expansum, la reducción en la población de esporas viables fue de 0,45 log esporas por $\mathrm{ml}$. El efecto antifúngico a bajas concentraciones de ácido peracético fue menor sobre $P$. roqueforti (reducción de 0,25 log esporas por $\mathrm{ml}$ ), pero cabe destacar que esta especie posee una resistencia particular a los ácidos orgánicos (Pitt y Hocking, 1997).

Sin embargo, otros estudios han puesto de manifiesto la efectividad de acido peracético como tratamiento antifúngico a bajas concentraciones. Garmendia y Vero han estudiado in vitro la acción de diferentes desinfectantes sobre $P$. expansum y $P$. italicum (patógeno poscosecha de citrus), observando que el ácido peracético a 80 ppm (0,008\%) tuvo la misma efectividad que el hipoclorito de sodio a 100 ppm. Si bien el hipoclorito se utiliza en general para el lavado de frutas y hortalizas (Garmendia y Vero, 2006), cabe destacar que en los últimos años se ha desestimado el uso del cloro y sus derivados considerando el riesgo medioambiental asociados al vertido de aguas con 
contaminantes y al posible riesgo para la salud debido a la presencia de compuestos potencialmente cancerígenos formados por la reacción del cloro con la materia orgánica presente en el agua (Silveira et al., 2008). Salomão y colaboradores han demostrado que el lavado de manzanas con soluciones de 50 y 80 ppm de ácido peracético pueden reducir en aproximadamente 1 y 1,5 ordenes logarítmicos, respectivamente, la carga de esporas de $P$. expansum por $g$ de fruta.

Tabla 1: Reducción de la carga de esporas fúngicas para diferentes concentraciones de ácido peracético luego de 30 min de exposición.

\begin{tabular}{|c|c|c|c|c|c|}
\hline \multirow{2}{*}{$\begin{array}{l}\text { Especie } \\
\text { Fúngica }\end{array}$} & \multirow{2}{*}{$\begin{array}{c}\text { Recuento } \\
\text { Inicial (esp/ml) }\end{array}$} & \multirow{2}{*}{$\begin{array}{c}\text { Agua* } \\
\text { (No Tratamiento) }\end{array}$} & \multicolumn{3}{|c|}{ Concentración de ácido peracético* } \\
\hline & & & $0,05 \%$ & $0,1 \%$ & $0,3 \%$ \\
\hline A. alternata & $2,40 \pm 0,14 \times 10^{6}$ & $\begin{array}{c}7,85 \pm 0,49 \times 10^{5} \\
(5,89)^{\mathrm{a}}\end{array}$ & $\begin{array}{c}3,50 \pm 0,70 \times 10^{4} \\
(4,54)^{a}\end{array}$ & $\begin{array}{c}4,00 \pm 0,00 \times 10^{3} \\
(3,60)\end{array}$ & $\begin{array}{l}<100 \\
(<2)^{c}\end{array}$ \\
\hline F. graminearum & $1,08 \pm 0,10 \times 10^{6}$ & $\begin{array}{c}6,00 \pm 0,36 \times 10^{5} \\
(5,78)^{a}\end{array}$ & $\begin{array}{c}2,13 \pm 1,30 \times 10^{4} \\
\quad(4,33)^{a}\end{array}$ & $\begin{array}{c}1,83 \pm 0,40 \times 10^{3} \\
(3,26)^{b}\end{array}$ & $\begin{array}{l}<100 \\
(<2)^{c}\end{array}$ \\
\hline A. ochraceus & $1,35 \pm 0,21 \times 10^{6}$ & $\begin{array}{c}3,63 \pm 2,29 \times 10^{6} \\
(6,56)^{\mathrm{a}}\end{array}$ & $\begin{array}{c}4,70 \pm 3,45 \times 10^{5} \\
(5,67)^{\mathrm{a}}\end{array}$ & $\begin{array}{c}3,08 \pm 1,37 \times 10^{4} \\
(4,49)^{a}\end{array}$ & $\begin{array}{l}<100 \\
(<2)^{b}\end{array}$ \\
\hline A. flavus & $1,24 \pm 0,19 \times 10^{6}$ & $\begin{array}{c}1,51 \pm 0,53 \times 10^{6} \\
(6,18)^{a}\end{array}$ & $\begin{array}{c}7,53 \pm 4,57 \times 10^{5} \\
(5,88)^{\mathrm{a}}\end{array}$ & $\begin{array}{c}8,20 \pm 5,71 \times 10^{5} \\
(5,91)^{\mathrm{a}}\end{array}$ & $\begin{array}{c}3,05 \pm 1,20 \times 10^{5} \\
(5,48)^{b}\end{array}$ \\
\hline A. niger & $1,21 \pm 0,27 \times 10^{6}$ & $\begin{array}{c}1,45 \pm 0,14 \times 10^{6} \\
(6,16)^{a}\end{array}$ & $\begin{array}{c}7,15 \pm 3,90 \times 10^{5} \\
(5,85)^{\mathrm{a}}\end{array}$ & $\begin{array}{c}9,75 \pm 6,32 \times 10^{5} \\
(5,99)^{\mathrm{a}}\end{array}$ & $\begin{array}{c}7,33 \pm 3,30 \times 10^{5} \\
(5,87)^{\mathrm{a}}\end{array}$ \\
\hline P. roqueforti & $1,20 \pm 0,28 \times 10^{6}$ & $\begin{array}{c}1,95 \pm 0,44 \times 10^{6} \\
(6,29)^{\mathrm{a}}\end{array}$ & $\begin{array}{c}1,11 \pm 0,14 \times 10^{6} \\
(6,05)^{\mathrm{a}}\end{array}$ & $\begin{array}{c}6,55 \pm 3,65 \times 10^{5} \\
(5,82)^{a}\end{array}$ & $\begin{array}{c}3,00 \pm 2,51 \times 10^{5} \\
(5,48) b\end{array}$ \\
\hline P. expansum & $1,70 \pm 0,42 \times 10^{6}$ & $\begin{array}{c}1,94 \pm 1,08 \times 10^{6} \\
(6,29)^{\mathrm{a}}\end{array}$ & $\begin{array}{c}6,88 \pm 1,19 \times 10^{5} \\
(5,84)^{\mathrm{a}}\end{array}$ & $\begin{array}{c}8,15 \pm 1,45 \times 10^{5} \\
(5,91)^{a}\end{array}$ & $\begin{array}{c}4,70 \pm 2,89 \times 10^{5} \\
(5,67)^{b}\end{array}$ \\
\hline
\end{tabular}

En el presente trabajo pudo observarse un aumento de la reducción de carga de esporas al incrementarse la concentración de ácido peracético resultando efectivo a una concentración del 0,3\% frente a todas las especies evaluadas, exceptuando a $A$. niger. Asimismo se ha podido observar que este tratamiento resultó sumamente eficaz en su capacidad antifúngica frente a $A$. alternata, $F$. graminearum y $A$. ochraceus.

Respecto a $A$. alternata y F. graminearum, la reducción de la carga de esporas viables fue mayor de 3,89 y 3,78 órdenes logarítmicos, respectivamente. Para $A$. ochraceus, este agente redujo en más de 4,56 órdenes logarítmicos la carga de esporas luego de 30 minutos de exposición, frente al tratamiento control (agua). Es de destacar la importancia del efecto antifúngico del ácido peracético sobre estas especies considerando que son importantes agentes causales de pudrición de frutas y hortalizas e importantes productoras de micotoxinas (Bottalico y Logrieco, 1998). Evitando el desarrollo de tales especies sobre frutas y hortalizas se evitarían las pérdidas económicas y el potencial riesgo a la salud del consumidor por la presencia de micotoxinas en los alimentos elaborados en base a estos productos. Cabe mencionar que en un estudio previo se han evaluado un total de 80 muestras de productos de tomate determinándose que el 49\% estaban contaminados con toxinas de Alternaria (Terminiello et al., 2006).

Otras sustancias "Generalmente Reconocidas como Seguras" (GRAS) también han sido estudiadas como potenciales agentes desinfectantes de frutas y hortalizas. Respecto a compuestos del oxígeno activo, el ozono y el peróxido de hidrogeno ha mostrado ser eficaces tanto para eliminar esporas de varias especies fúngicas como también por su actividad bactericida. Estos agentes son totalmente inocuos. Sin embargo, la efectividad del ozono disminuye en caso de existir materia orgánica en el agua y la aplicación del peróxido de hidrogeno está limitada solo a algunas frutas y hortalizas, ya que puede producir blanqueamiento de pigmentos (fresas y frambuesas). Compuestos alcalinos tales como el fosfato trisódico y el bicarbonato de sodio también han sido estudiados en su capacidad antimicrobiana para la desinfección de estos productos. El uso de estas sustancias se ve limitado 
debido a los problemas asociados a la disposición de las soluciones, que presentan elevado $\mathrm{pH}, \mathrm{y}$ a la restricción con respecto a la descarga ambiental de fosfatos (Garmendia y Vero, 2006). En futuros estudios, y partir de estos resultados obtenidos in vitro, se llevarán a cabo ensayos sobre frutas y hortalizas a fin de evaluar la efectividad antifúngica del ácido peracético in vivo como así también su efecto sobre la fisiología de estos productos.

\section{CONCLUSIONES}

El ácido peracético puede resultar una alternativa sumamente interesante para el control poscosecha de las pudriciones causadas por mohos en frutas y hortalizas como tratamiento no contaminante, respetuoso del medio ambiente, contribuyendo asimismo a proteger la salud del consumidor.

\section{AGRADECIMIENTOS}

Los autores agradecen a Perway SRL por el suministro del acido peracético (Perwy Box 90). También al Profesor Dr. Félix Franco y al Ing. Juan Segura por su colaboración en el análisis estadístico de los datos.

\section{REFERENCIAS}

Bastos, M. y otros 4 autores, The effect of the association of sanitizers and surfactant in the microbiota of the Cantaloupe (Cucumis melo L.) melon surface, Food Control, 16 (4), 369-373 (2005)

Bautista Baños S., El Control Biológico en la Reducción de Enfermedades Poscosecha en Productos Hortofrutícolas: Uso de Microorganismos Antagónicos, Rev. Iber Tecnología Poscosecha, 8 (1), 1-6 (2006)

Bottalico, A. y A. Logrieco, Alternaria Plant diseases in Mediterranean Countries and Associated Mycotoxins, En: Chelkowski, J.; Visconti A. (Eds), Alternaria, Biology, Plant Disease and Metabolites, Amsterdam, Elsevier, volumen 3, 209-232 (1992)

Bottalico, A. y A. Logrieco, Toxigenic Alternaria Species of Economic Importance, En: Sinha, K. K.; Bhatnagar, D. (Eds), Mycotoxins in Agriculture and Food Safety. Nueva York. Marcel Dekker, Inc., 65108 (1998)

Brogden, K.A., Antimicrobial Peptides: Pore formers or metabolic inhibitors in bacteria?, Nature Reviews Microbiology, 3, 238-250 (2005)

Carrillo, L., Los hongos de los alimentos y forrajes, 1a edición, 44-69, Universidad de Salta, Salta, Argentina (2003).

F.D.A., Analysis and evaluation of preventive control measures for the control and reduction/elimination of microbial hazards on fresh and fresh-cut produce - Method to Reduce/Eliminate Pathogens from fresh and fresh-cut produce (en línea), 2001. http://www.cfsan.fda.gov/ comm/ift3-5.html. Acceso: 28 de noviembre (2008)

Garmendia, G. y S. Vero Méndez, Métodos para la desinfección de frutas y hortalizas, Horticultura: Revista de frutas, hortalizas, flores, plantas ornamentales y de viveros, ISSN 1132-2950, (en línea), No 197, 18-27, 2006, http://dialnet.unirioja.es/servlet/articulo?codigo=2153512. Acceso: 6 de Abril (2009)

Hernández Rodríguez, A., Aportaciones al estudio de la actividad antimicrobiana de los antisépticos y desinfectantes, Tesis de Doctorado, Badalona, Universidad Autónoma de Barcelona (2006)

King, A.D. Jr. y J.E. Schade, Alternaria toxins and their importance in food, Journal of Food Protection, 47(11), 886-901 (1984) 
Logrieco, A. y otros 4 autores, Epidemiology of Toxigenic Fungi and their Associated Mycotoxins for some Mediterranean Crops, European Journal of Plant Pathology 109, 645 (2003)

López, L.V., J.R. Romero y F.V. Ureta, Tratamientos de desinfección de lechugas (Lactuca sativa) y frutillas (Fragaria chiloensis), Archivos Latinoamericanos de Nutrición, 51 (4), 376-381 (2001)

López, L.V., J.R. Romero y F.V. Ureta, Acción germicida in vitro de productos desinfectantes de uso en la industria de alimentos, Archivos Latinoamericanos de Nutrición, 52 (1), 74-76 (2002)

Mari, M. y otros 3 autores, Peracetic acid and chlorine dioxide for postharvest control of Monilinia laxa in stone fruits, Plant Dis., 83, 773-776 (1999)

Muñoz, A., Caracterización de distintos péptidos antimicrobianos con actividad frente a hongos fitopatógenos de interés agroalimentario, Tesis de Doctorado, Valencia, Universidad Politécnica de Valencia y Grupo de Poscosecha, Instituto de Agroquímica y Tecnología de Alimentos (2008)

Palou, L., Evaluación de Alternativas para el Tratamiento Antifúngico en Poscosecha de Cítricos de Producción Integrada, Horticultura: Revista de frutas, hortalizas, flores, plantas ornamentales y de viveros, ISSN 1132-2950, (en línea), $\mathrm{N}^{\mathrm{O}}$ 200, 82-93, 2007, http://www.horticom.com/revistasonline/revistas/rh200/082_093.pdf. Acceso: 6 de Abril (2009)

Pitt, J. I. y A. D. Hocking, Fungi and Food Spoilage, $2^{\mathrm{a}}$ edición, 469-481, Blackie Academic and Professional, Londres, Inglaterra (1997)

Raybaudi-Mansilla, R.M., R.S. Fortuna y O.M. Belloso, Uso de agentes antimicrobianos para la conservacion de frutas frescas y frescas cortadas. I Simpósio Ibero-Americano de Vegetais Frescos Cortados, 15-21, San Pedro, SP Brasil, Abril (2006)

Rodgers, S.L. y otros 3 autores, A comparison of different chemical sanitizer for inactivating Escherichia coli O157:H7 y Listeria monocytogenes in solution and in apple, lettuce, strawberries and cantaloupe, Journal of Food Protection, 67 (4), 721-731 (2004)

Salomão, B.C.M. y otros 3 autores, Efficacy of sanitizing treatments against Penicillium expansum inoculated on six varieties of apples, Journal of Food Protection, 71 (3), 643-647 (2008)

S.E.N.A.S.A., Limpieza y desinfección - El ácido peracético (2006), http://www.senasa.gov.ar/contenido.php?to=n\&in=888\&io=4117\#. Acceso: 28 noviembre (2008)

Silveira, A.C. y otros 3 autores, Alternative sanitizers to chlorine for use on fresh-cut "galia" (cucumis melo var. catalupensis) melon, Journal of Food Science 73 (9), M405-M411, (2008)

Srebernich, S.M., Using chlorine dioxide and peracetic acid as substitutes for sodium hypocloride in the sanitization of minimally processed green seasoning, Ciencia e Tecnologia de Alimentos, 27 (4), 744-750 (2007)

Terminiello, L., A. Patriarca, G. Pose y V. Fernández Pinto, Occurrence of Alternariol, Alternariol Monomethyl Ether, and Tenuazonic Acid in Argentinean Tomato Puree, Mycotoxin Research, 22 (4), 236-240 (2006).

Wright J.R. y otros 4 autores, Reduction of Escherichia coli 0157:H7 on apples using wash and chemical sanitizer treatments, Dairy Food Environ Sanit, 20, 120-126 (2000) 